\title{
ASESMEN RESIKO BENCANA MENGGUNAKAN METODE KUALITATIF PADA KELURAHAN MALASILEN
}

\author{
${ }^{1}$ Angga Saputra, ${ }^{2}$ Fadhiel Imam $M,{ }^{3}$ Nurcahyanto \\ Program Studi Teknik Sipil, Universitas Muhammadiyah Sorong \\ Email : Fajartawabin@gmail.com
}

\begin{abstract}
Abstrak
Bencana alam merupakan suatu ancaman yang dapat menimpa suatu kawasan dimanapun berada. Ini tentunya harus menjadi perhatian yang penting dalam rangka upaya pengurangan resiko bencana. Kelurahan Malasilen merupakan salah satu Kelurahan yang berlokasi di Distrik Sorong Utara, tepatnya di jalan KPR Polisi. Seperti yang diketahui, daerah Kota Sorong sering terjadi bencana seperti kebanjiran, kekeringan, gempa bumi, dan lainnya. Pada penelitian ini mengasesmen resiko bencana tersebut. Metode yang digunakan adalah asesmen resiko bencana menggunakan metode kualitatif (Qualitative Risk Hazard Assessment). Parameter dan indikator penilaian yang digunakan mengacu pada British Columbia Provincial Emergency Program. Hasil dari penelitian menunjukkan bahwa resiko yang paling dominan pada daerah ini adalah bencana gempa bumi kemudian disusul oleh letusan/erupsi gunung berapi.
\end{abstract}

Kata Kunci : Asesmen Resiko Bencana, Qualitative Risk Hazard Assessment, Kelurahan Malasilen

\section{Pendahuluan}

Kelurahan Malasilen merupakan salah satu daerah di Distrik Sorong yang terkena dampak terhadap banjir yang terjadi pada tanggal 27 juni 2018. Sehingga, mengakibatkan terendamnya rumah-rumah warga serta dapat melumpuhkan jalur transportasi. Selain itu, gempa bumi yang terkadang dapat terjadi merupakan suatu ancaman tersendiri bagi masyarakat Kota Sorong, karena dapat berakibat pada rusaknya struktur dan infrastruktur yang ada. Kemudian bencana lain pun yang terkadang terjadi seperti kekeringan. Hal ini tentunya diperlukan suatu asesmen dalam rangka mengidentifikasi bencana mana yang memiliki resiko paling tinggi.

Pengurangan resiko ini sangat penting sebagai langkah mitigasi. Upaya mitigasi perlu dilakukan untuk mengidentifikasi bencana yang akan terjadi dikemudian hari dengan mengambil langkah antisipasi. Hal ini dilakukan dalam rangka untuk mengurangi resiko yang ditimbulkan sehingga tingkat kerugian dan korban yang berjatuhan dapat diminimalisir (Saputro, 2018).

Ada beberapa metode untuk melakukan asesmen resiko bencana yaitu metode kualitatif, metode kuantitatif dan metode semi-kuantitatif. Metode-metode tersebut memiliki berbagai keunggulan masing-masing. Metode kualitatif merupakan metode yang paling simpel digunakan dalam asesmen resiko terhadap bencana. Pada metode ini indikator dapat mengekspresikan tingkat resiko dari bencana tersebut seperti: sangat rendah, rendah, sedang, tinggi, atau sangat tinggi. Indikator ini bergantung pada standar acuan para ahli yang dipakai.

Standar acuan yang dipakai pada penelitian ini adalah mengacu pada British Columbia Provincial Emergency Program. Terdapat beberapa aspek yang diperhitungkan dalam acuan ini diantaranya adalah kematian (fatality), terluka (injured), fasilitas vital (critical facilities), fasilitas umum pendukung (life-lines), kerusakan harta milik (property damage), lingkungan (environment), dampak ekonomi dan sosial (economics and sosial impacts). Berdasarkan datadata tersebut maka dapat disajikan data dalam bentuk matrikulasi resiko/RiskMatrix. 


\section{Tujuan}

Penelitian ini bertujuan untuk melakukan langkah asesmen resiko bencana yang mungkin terjadi di daerah Kelurahan Malasilen, Distrik Sorong Utara, Kota Sorong dengan mempertimbangkan beberapa bencana yang berpotensi pada daerah tersebut.

\section{Metode}

Metode yang digunakan pada penelitian ini mengikuti flowchart yang tersaji pada Gambar 1 di bawah ini.

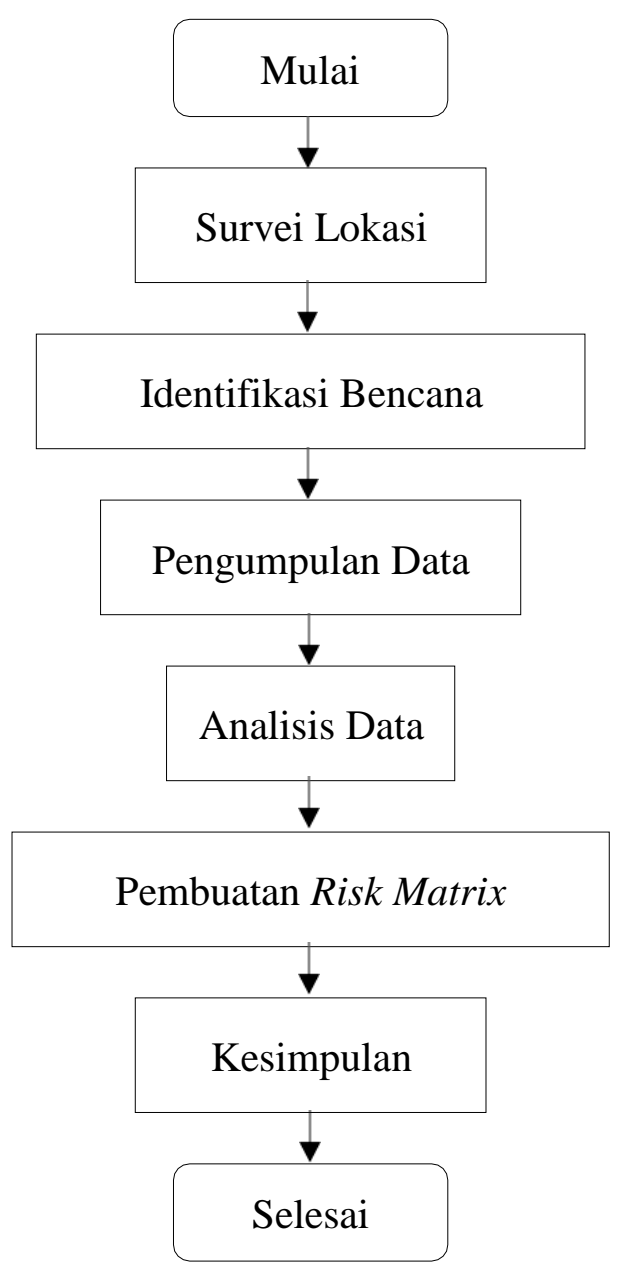

Gambar 1 Flowchart Metode Penelitian

\section{Analisis dan Pembahasan}

\section{Survei Lokasi dan identifikasi bencana}

Penelitian dilakukan pada daerah Kelurahan Malasilen, Distrik Sorong Utara, Kota Sorong. Kelurahan ini memiliki luas sekitar 20,99 $\mathrm{km}^{2}$. Survei lokasi dilakukan untuk mengetahui kondisi tempat penelitian secara langsung. Selain itu, terdapat beberapa data sekunder yang diperlukan sebagai bahan pertimbangan dalam melakukan proses analisis. Data sekunder yang diperlukan seperti data penduduk daerah Kelurahan Malasilen. Adapun tempat lokasi penelitian tersaji pada Gambar 2 berikut ini. 


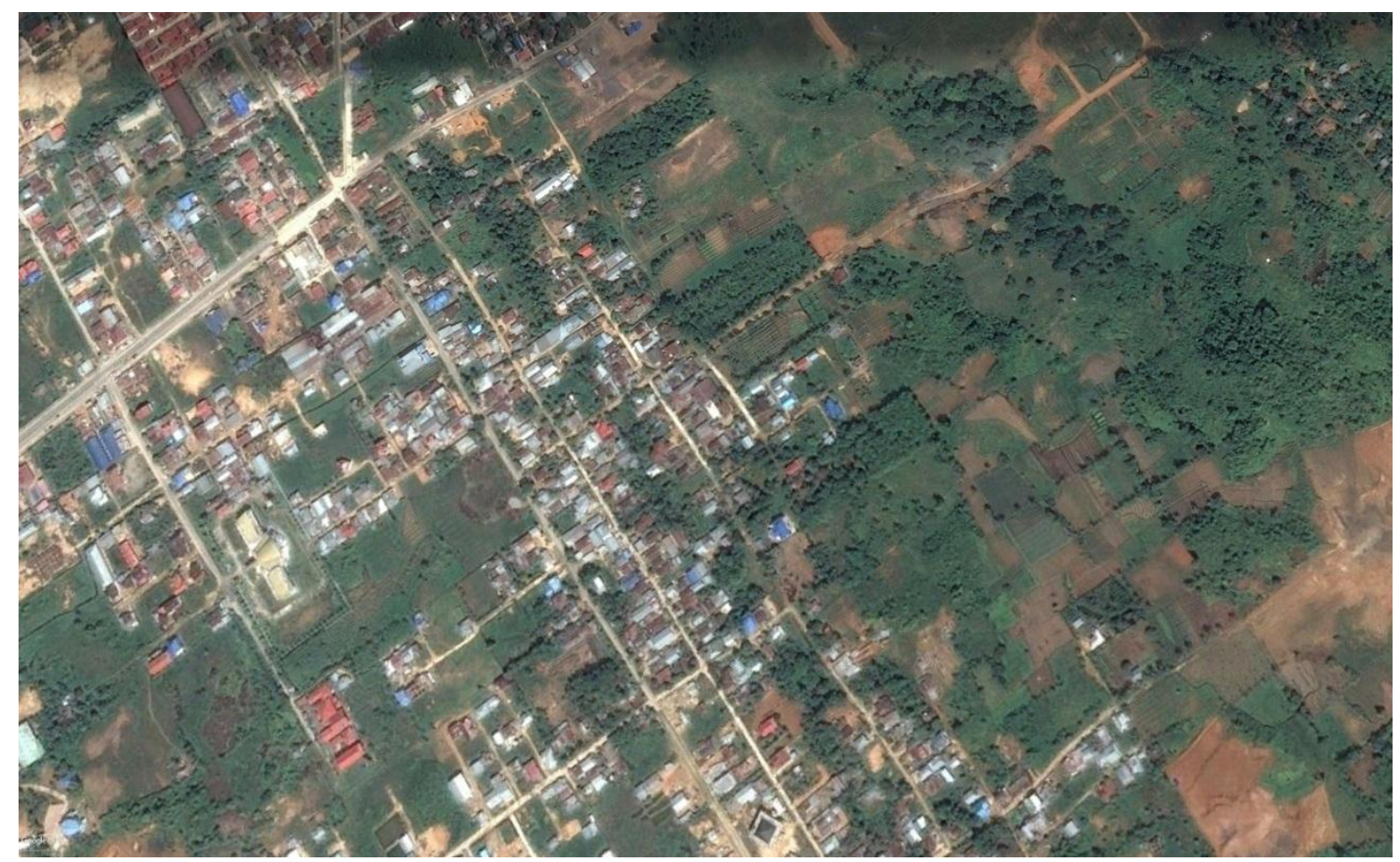

Gambar 2 Lokasi Penelitian (Google Erath Pro, 2018)

\section{Pengumpulan Data}

Pengumpulan data terkait penelitian terhadap Kelurahan Malasilen dilakukan dengan mendatangi kantor Kelurahan Malasilen untuk mengetahui jumlah penduduk dan penyebarannya menurut usia, dan tingkat pendidikan masyarakat sekitar. Setelah itu, melakukan wawancara langsung terhadap perangkat desa setempat. Kantor Kelurahan Malasilen terlihat pada Gambar 3 berikut.
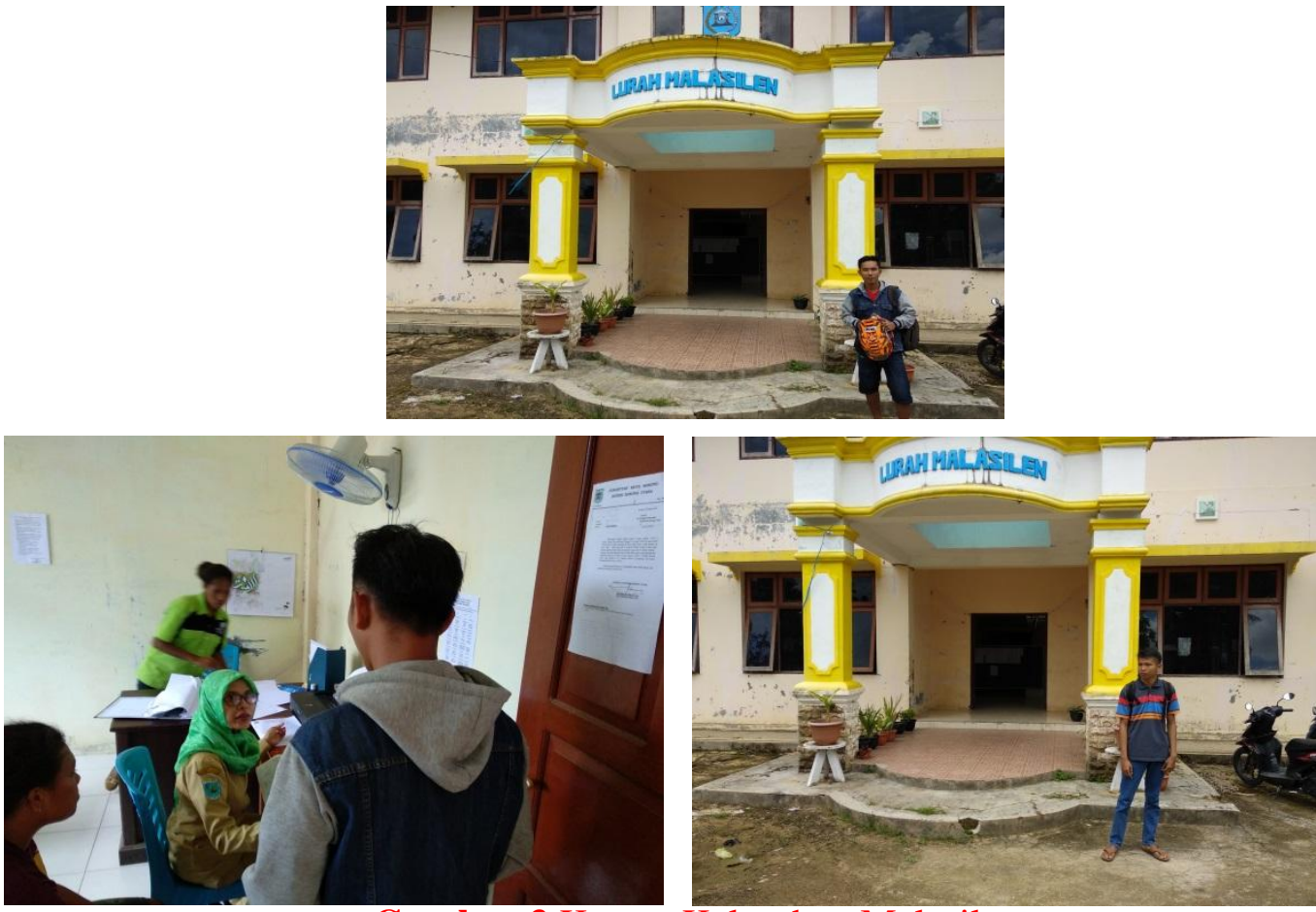

Gambar 3 Kantor Kelurahan Malasilen 
Dari hasil survei yang dilakukan maka diperoleh beberapa data yaitu jumlah penduduk berdasarkan jenis kelamin pada Tabel 1, jumlah penduduk menurut pekerjaan pada Tabel 2, dan Penyebaran penduduk per kelurahan tahun 2017 pada Tabel 3.

Tabel 1 Jumlah Penduduk Berdasarkan Jenis Kelamin

\begin{tabular}{|c|c|c|c|c|c|}
\hline & & \multicolumn{2}{|c|}{ Jenis Kelamin (Jiwa) } & \multirow{2}{*}{$\begin{array}{c}\text { Jumlah } \\
\text { Total }\end{array}$} & \multirow{2}{*}{ Jumlah KK } \\
\cline { 1 - 3 } No & Pendukuhan & $\begin{array}{c}\text { Laki- } \\
\text { Laki }\end{array}$ & Perempuan & & \\
\hline 1 & Matalamagi & 3.659 & 3.200 & 6.859 & - \\
\hline 2 & Malasilen & 2.579 & 2.199 & 4.778 & 1.270 \\
\hline 3 & Malanu & 3.614 & 3.356 & 6.970 & - \\
\hline 4 & Sawagumu & 3.809 & 3.059 & 6.868 & - \\
\hline & JUMLAH & $\mathbf{1 2 . 9 4 1}$ & $\mathbf{1 1 . 8 1 4}$ & $\mathbf{2 5 . 4 7 5}$ & $\mathbf{1 . 2 7 0}$ \\
\hline
\end{tabular}

Sumber : Data Administrasi Kelurahan Malasilen 2017

Tabel 2 Jumlah Penduduk menurut Pekerjaan

\begin{tabular}{|c|c|}
\hline Pendidikan Terakhir & Jumlah \\
\hline PNS & 162 \\
\hline Pegawai Swasta & 399 \\
\hline ABRI & 43 \\
\hline Wiraswasta/Pedagang & 246 \\
\hline Tani & 240 \\
\hline Buruh Tani & 71 \\
\hline Pengusaha & 55 \\
\hline Nelayan & 5 \\
\hline Sopir & 8 \\
\hline Pensiunan & 14 \\
\hline Sumber: Kant Kelurahan
\end{tabular}

Sumber: Kantor Kelurahan Malasilen 
Tabel 3 Penyebaran Penduduk Per Kelurahan Tahun 2017

\begin{tabular}{|c|c|c|c|c|}
\hline \multirow{2}{*}{ No } & \multirow{2}{*}{ Struktur Umur } & \multicolumn{2}{|c|}{ Jenis Kelamin } & \multirow{2}{*}{ Jumlah } \\
\cline { 3 - 4 } 1 & $0-14$ & 3990 & 4113 & 8103 \\
\hline 2 & $15-24$ & 2525 & 2472 & 4997 \\
\hline 3 & $25-49$ & 5315 & 4825 & 10140 \\
\hline 4 & $>50$ & 1052 & 906 & 1958 \\
\hline \multicolumn{2}{|c|}{ Jumlah Total } & 12882 & 12316 & 25198 \\
\hline \multicolumn{2}{|c|}{ Presentase (\%) } & 51 & 49 & 100 \\
\hline
\end{tabular}

Sumber : https//:sorongkota.bps.go.id

Dari data-data diatas kemudian dilakukan penentuan parameter dan indikator yang akan digunakan untuk melakukan penilaian.

\section{Indikator Penilaian British Columbia Provincial Emergency Program}

Pada penelitian ini menggunakan indikator penilaian yang mengacu pada British Columbia Provincial Emergency Program yang memuat beberapa aspek seperti kematian (fatality), terluka (injured), fasilitas vital (critical facilities), fasilitas umum pendukung (lifelines), kerusakan harta milik (property damage), lingkungan (environment), dampak ekonomi dan sosial (economics and sosial impacts). Untuk penjelasan mengenai kriterianya tersaji pada Tabel 6 sampai Tabel 12. Adapun Tabel 5 menjelaskan kriteria tentang kemungkinan bencana tersebut terjadi.

Tabel 4 Kemungkinan Bahaya

\begin{tabular}{|c|c|c|}
\hline Skala & Keterangan & Kriteria \\
\hline 1 & Sangat tidak mungkin & $0 \%$ to $5 \%$ \\
\hline 2 & Tidak mungkin & $6 \%$ to $15 \%$ \\
\hline 3 & Sedang & $16 \%$ to $60 \%$ \\
\hline 4 & Mungkin & $61 \%$ to $60 \%$ \\
\hline 5 & Sangat mungkin & $>90 \%$ \\
\hline \hline
\end{tabular}

Tabel 5 Korban Meninggal

\begin{tabular}{|c|c|c|}
\hline Skala & Keterangan & Kriteria \\
\hline 1 & Sangat Rendah & $0-4$ \\
\hline 2 & Rendah & $4-10$ \\
\hline 3 & Tinggi & $10-50$ \\
\hline 4 & Sangat Tinggi & $>50$ \\
\hline \hline
\end{tabular}

Tabel 6 Korban Luka-luka

\begin{tabular}{|c|c|c|}
\hline Skala & Keterangan & Kriteria \\
\hline 1 & Sangat Rendah & $0-4$ \\
\hline 2 & Rendah & $4-50$ \\
\hline 3 & Tinggi & $50-2000$ \\
\hline 4 & Sangat Tinggi & $\geq 2000$ \\
\hline \hline
\end{tabular}


Tabel 7 Fasilitas Vital Kritis

\begin{tabular}{|c|c|c|}
\hline Skala & Keterangan & Kriteria \\
\hline 1 & Sangat Rendah & Relokasi sementara \\
\hline 2 & Rendah & Tutup dalam beberapa hari \\
\hline 3 & Tinggi & Kehilangan kemampuan hingga lebih 50\% \\
\hline 4 & Sangat Tinggi & Pulih dalam waktu lama \\
\hline
\end{tabular}

Tabel 8 Fasilitas Umum Pendukung

\begin{tabular}{|c|c|c|}
\hline Skala & Keterangan & Kriteria \\
\hline 1 & Sangat Rendah & Terganggu sementara \\
\hline 2 & Rendah & Terganggu selama beberapa hari \\
\hline 3 & Tinggi & Terganggu selama 1 minggu \\
\hline 4 & Sangat Tinggi & Tidak berfungsi dalam waktu lama \\
\hline
\end{tabular}

Tabel 9 Kerusakan Harta Milik

\begin{tabular}{|c|c|c|}
\hline Skala & Keterangan & Kriteria \\
\hline 1 & Sangat Rendah & Kerusakan minimal \\
\hline 2 & Rendah & Kerusakan ringan dan cakupan area lokal \\
\hline 3 & Tinggi & Kerusakan berat dan cakupan area lokal \\
\hline 4 & Sangat Tinggi & Kerusakan berat dan cakupan area luas \\
\hline
\end{tabular}

Tabel 10 Lingkungan

\begin{tabular}{|c|c|c|}
\hline Skala & Keterangan & Kriteria \\
\hline 1 & Sangat Rendah & Kerusakan minimal \\
\hline 2 & Rendah & Kerusakan ringan dan cakupan area lokal \\
\hline 3 & Tinggi & Kerusakan berat dan cakupan area lokal \\
\hline 4 & Sangat Tinggi & Kerusakan berat dan cakupan area luas \\
\hline
\end{tabular}

Tabel 11 Sosial dan Ekonomi

\begin{tabular}{|c|c|c|}
\hline Skala & Keterangan & Kriteria \\
\hline 1 & Sangat Rendah & Berdampak Sementara pada cakupan area lokal \\
\hline 2 & Rendah & Berdampak Sementara pada cakupan area luas \\
\hline 3 & Tinggi & Berdampak lama pada cakupan area luas \\
\hline 4 & Sangat Tinggi & Gangguan berdampak lama \\
\hline
\end{tabular}

Jenis bencana yang akan diperhitungkan pada asesmen ini adalah Banjir, kekeringan, gempa bumi, tanah longsor. Asesmen pada bencana tersebut dinilai dengan menggunakan motede Qualitative Risk Hazard Assessment.

Setelah menentukan parameter dan nilai yang akan digunakan kemudian langsung mengevaluasi lokasi Kelurahan Malasilen. Berdasarkan hasil survey pengumpulan data wawancara terhadap perangkat desa setempat, maka data dapat disajikan seperti pada Tabel 12 sampai Tabel 14 berikut ini. 
Tabel 12 Hasil Pengumpulan Data

\begin{tabular}{|l|c|c|c|c|}
\hline \multirow{2}{*}{ Bencana } & \multirow{2}{*}{$\begin{array}{c}\text { Probabilitas } \\
\text { kejadian }\end{array}$} & Kematian & $\begin{array}{c}\text { Dampak/Konsekuensi } \\
\text { Luka }\end{array}$ & Dampak ke fasilitas \\
\cline { 4 - 5 } & & 0 & 0 & Pulih dalam waktu lama \\
\hline Gempa bumi & $16 \%$ to $60 \%$ & 0 & 0 & - \\
\hline Gunung berapi & $0 \%$ to $5 \%$ & 0 & 0 & - \\
\hline Tsunami & $0 \%$ to $5 \%$ & 0 & 0 & - \\
\hline Longsor & $0 \%$ to $5 \%$ & 0 & 0 & Terganggu sementara \\
\hline Banjir & $61 \%$ to $60 \%$ & 0 & 0 & - \\
\hline Kekeringan & $0 \%$ to $5 \%$ & 0 & & \\
\hline
\end{tabular}

Tabel 13. Hasil Pengumpulan data

\begin{tabular}{|l|c|c|}
\hline \multirow{2}{*}{ Bencana } & \multicolumn{2}{|c|}{ Dampak/Konsekuensi } \\
\cline { 2 - 3 } & Fasilitas umum pendukung & Kerusakan properti \\
\hline Gempa bumi & Terganggu sementara & Rumah \\
\hline Gunung berapi & - & - \\
\hline Tsunami & - & - \\
\hline Longsor & - & - \\
\hline Banjir & Terganggu sementara & Rumah \\
\hline Kekeringan & - & - \\
\hline
\end{tabular}

Tabel 14. Hasil Pengumpulan data

\begin{tabular}{|c|c|c|}
\hline \multirow{2}{*}{ Hazard } & \multicolumn{2}{|c|}{ Dampak/Konsekuensi } \\
\hline & Lingkungan & Sosial \& ekonomi \\
\hline Gempa bumi & & Gangguan berdampak lama \\
\hline \multirow[t]{2}{*}{ Gunung berapi } & & \\
\hline & & - \\
\hline Tsunami & & - \\
\hline \multirow[t]{2}{*}{ Longsor } & & \\
\hline & & - \\
\hline \multirow[t]{2}{*}{ Banjir } & & Gangguan Berdampak Sementara \\
\hline & & - \\
\hline Kekeringan & & - \\
\hline
\end{tabular}

Berdasarkan hasil asesmen terhadap beberapa parameter yang diperhitungkan maka dilakukan penilaian sesuai indikator yang sesuai dari masing-masing bencana yang dimasukkan. Ini dimaksudkan untuk melihat seberapa besar dampak yang ditimbulkan. Hasil penilaian dampak tersebut tersaji pada Tabel 15 berikut ini. 
Tabel 15 Penilaian dampak/konsekuensi

\begin{tabular}{|c|c|c|c|c|c|c|c|c|c|}
\hline \multirow[b]{2}{*}{ Bencana } & \multirow{2}{*}{$\begin{array}{c}\text { Kemungkinan } \\
\text { Terjadi }\end{array}$} & \multicolumn{2}{|c|}{ Dampak Konsekuensi } & \multirow[b]{2}{*}{ Fasilitas } & \multirow[b]{2}{*}{ Fasilitas } & \multirow[b]{2}{*}{ Kerusakan } & \multirow[b]{2}{*}{ Lingkungan } & \multirow[b]{2}{*}{ Sosial } & \multirow[b]{2}{*}{$\mathrm{Jml}$} \\
\hline & & Meninggal & Luka-Iuka & & & & & & \\
\hline & & & & Vital & Umum & Harta & & Ekonomi & \\
\hline Gempa Bumi & 3 & 1 & 1 & 1 & 1 & 2 & 2 & 1 & 12 \\
\hline Gunung Berapi & 1 & 1 & 1 & 1 & 1 & 1 & 1 & 1 & 8 \\
\hline Tsunami & 1 & 1 & 1 & 1 & 1 & 1 & 1 & 1 & 8 \\
\hline Longsor & 1 & 1 & 1 & 1 & 1 & 1 & 1 & 1 & 8 \\
\hline Banjir & 5 & 1 & 2 & 1 & 2 & 2 & 2 & 1 & 16 \\
\hline Kekeringan & 2 & 1 & 1 & 1 & 1 & 1 & 1 & 1 & 9 \\
\hline
\end{tabular}

Tabel 16 menunjukkan hasil rekapitulasi dari asesmen terhadap bencana mungkin terjadi di daerah Distrik Sorong Utara, Kelurahan Malasilen, Kota Sorong. Hasil skor penilaian dampak terbesar adalah pada bencana Banjir yaitu sebanyak 16 poin. Hal ini tentunya wajar mengingat di daerah Kota Sorong sering terjadi Hujan lebat pada musim Hujan. Setelah itu potensi bencana yang besar berikutnya adalah berasal dari gempa bumi karena Kota Sorong berada pada sesar gempa.. Nilai-nilai tersebut kemudian dibuat dalam suatu matrikulasi resiko/risk matrix. Matrikulasi Resiko bencana pada desa Imogiri tersaji pada Gambar 4 berikut.

\begin{tabular}{|c|c|c|c|c|c|c|}
\hline & Kemungkinan & \multicolumn{5}{|c|}{ Tingkat Dampak } \\
\hline & Terjadi & Minimal & Sedikit & Sedang & Parah & Sangat parah \\
\hline 5 & Sangat Mungkin & & & & & \\
\hline 4 & Mungkin & & & Banjir & & \\
\hline 3 & Sedang & & $\begin{array}{l}\text { Gempa } \\
\text { bumi }\end{array}$ & & & \\
\hline 2 & Tidak Mungkin & & & & & \\
\hline & Sangat Tidak & & & & & \\
\hline & Mungkin & & & & & \\
\hline & Skala Dampak & Sangat Rendah & Rendah & Sedang & Tinggi & Sangat Tinggi \\
\hline & Skor & $1-6$ & $7-12$ & $13-18$ & $19-23$ & $24-28$ \\
\hline
\end{tabular}

Gambar 4 Matrikulasi Resiko Bencana di Sekitar Kelurahan Malasilen

\section{Kesimpulan}

Dari hasil asesmen resiko (risk assessment) dengan menggunakan metode qualitative risk hazard assessment diperoleh hasil bahwa pada Kelurahan Malasilen, bencana/hazard yang paling dominan atau terparah itu adalah Banjir. Salah satu penyebabnya karena mengingat kondisi Kota Sorong sering terjadi hujan lebat. Banjir pada tahun 2017 menimbulkan rumah sebagian terendam dan mengakibatkan Transportasi darat terganggu sementara akbibat banjir. 


\section{Daftar Pustaka}

Columbia, British (2004). Hazard, Risk, and Vurnerability Analysis Tool Kit. Provincial Emergency Program.

https://WWW.google.com/map

https://sorongkota.bps.go.id

Kantor Kelurahan Malasilen 